\title{
INFORMAÇÓES SOBRE A INFEÇÃO, TRANSMISSÃO E VACINA CONTRA O PAPILOMAVÍRUS HUMANO (HPV) AOS ADOLESCENTES: RELATO DE EXPERIÊNCIA DURANTE A PANDEMIA DA COVID-19
}

\author{
INFORMATION ON HUMAN PAPILLOMAVIRUS (HPV) INFECTION, \\ TRANSMISSION AND VACCINE TO ADOLESCENTS: EXPERIENCE \\ REPORT DURING THE COVID-19 PANDEMIC
}

Juliane Oliveira Brum ${ }^{1}$, Tainá Wagner ${ }^{1}$, Samuel Felipe Atuati ${ }^{1}$, Francieli Larissa Zamboni ${ }^{1}$, Adriana Marques da Silva ${ }^{1}$ e Vera Regina Medeiros Andrade ${ }^{1}$

${ }^{1}$ Universidade Integrada do Alto Uruguai e das Missóes - URI Santo Ângelo, Santo Ângelo, Rio Grande do Sul, Brasil.

\section{RESUMO}

A infecção por Papilomavírus humano (HPV) é o principal fator de risco para o desenvolvimento do câncer do colo do útero. A prevenção para esse tipo de infecção pode ser feita com o uso de preservativos, durante as relaçóes sexuais, por meio da vacina contra o HPV e pelo exame preventivo Papanicolaou. $\mathrm{O}$ artigo tem por objetivo relatar uma atividade de extensão, desenvolvida durante a pandemia da Covid-19, para promover a conscientizaçáo da importância da vacina contra o Papilomavírus humano (HPV) para jovens e adolescentes. Foi elaborado um vídeo no site "PowToon" para criar uma animação explicativa de forma simples e didática, utilizando figuras e palavras chaves juntamente com narração, explicando o que é o vírus do HPV, formas de contagio e meios de prevenção. Um formulário com questôes básicas que poderiam ser respondidas com informaçôes mencionadas no vídeo, foi encaminhado junto com o vídeo. Esse vídeo foi enviado pra escolas do municio de Santo Ângelo, Porto Lucena, Nova Candelária e Roque Gonzales, na regiấo das Missôes, RS, para alunos do $6^{\circ}$ ao $9^{\circ}$ ano. O projeto alcançou 4 instituiçóes de ensino que estavam com aulas online. Concluímos que é importante difundir informaçóes sobre a vacina contra o HPV aos adolescentes e jovens, para que tenham compreensão da prevenção precoce e o quanto ela é necessária, pois por meio dela podemos prevenir a infecção pelo HPV, evitando a evolução de lesóes pré-cancerosas e cancerosas, como o câncer de colo do útero. No entanto, a pandemia da Covid-19 dificultou essa atividade, limitando muito a divulgaçáo destas informações aos adolescentes.

Descritores: Adolescente; Infecçôes por Papillomavírus; Vacinação. 


\section{ABSTRACT}

Incluir resumo em inglês. Texto justificado em itálico (fonte Calibri, tamanho 11, espaço simples) Human Papillomavirus (HPV) infection is the main risk factor for the development of cervical cancer. Prevention for this type of infection can be done with the use of condoms, during sexual intercourse, through the HPV vaccine and the preventive Pap smear. The aims to report an extension activity, developed during the Covid-19 pandemic, to raise awareness of the importance of the Human Papillomavirus (HPV) vaccine for young people and adolescents. A video was created on the "PowToon" website to create an explanatory animation in a simple and didactic way, using pictures and keywords along with narration, explaining what the HPV virus is, ways of spreading it and means of prevention. A form with basic questions that could be answered with information mentioned in the video was sent along with the video. This video was sent to schools in the municipality of Santo Ângelo, Porto Lucena, Nova Candelaria and Roque Gonzales, in the region of Missóes, RS, for students from 6 th to 9 th grade. The project reached 4 educational institutions that were offering online classes. We conclude that it is important to disseminate information about the HPV vaccine to adolescents and young people, so that they understand early prevention and how much it is necessary, because through it we can prevent HPV infection, preventing the evolution of precancerous lesions and cancerous, such as cervical cancer. However, the Covid-19 pandemic made this activity difficult, greatly limiting the dissemination of this information to adolescents.

Descriptors: Adolescent; Papillomavirus Infections; Vaccination.

\section{INTRODUÇÁO}

O câncer do colo do útero tem como principal fator de risco a infecção pelo Papilomavírus humano (HPV). No Brasil, conforme o Instituto Nacional do Câncer (INCA), foi estimado um número de 16.590 novos casos de câncer do colo do útero, para o triênio 2020-2022. ${ }^{1}$ Em 2019, ocorreram 6.596 óbitos por esta neoplasia com mulheres brasileiras, representando uma taxa de 5,33/100 mil mulheres. Já, no ano de 2020, ocorreram 16.710 novos casos, estimativa de 15,38 casos a cada 100 mil mulheres. ${ }^{1}$

O HPV pertence à família Papillomaviridae, é um vírus de DNA dupla fita e circular. Seu genoma é constituído por regióes codificadoras classificadas em precoce (early) e tardia (late). A regiáo precoce contém os genes E1, E2, E4, E5, E6 e E7. Os genes E1 e E2 têm a função de replicação do HPV e o E2 também é responsável ela transcrição do DNA do vírus. $\mathrm{O}$ gene E4 possui uma proteína que realiza mutaçóes e libera partículas virais. Os genes E5, E6, e E7 promovem transformaçóes celulares. Na regiáo tardia, os genes L1 e L2 formam o capsídeo viral, nele são encontrados cerca de 360 cópias da proteína L1, a qual fica organizada em 72 pentâmeros em uma rede icosaédrica e 12 cópias da proteína L2. ${ }^{2,3,4}$. A descoberta de que a proteína L1 é capaz de organizar-se em estruturas icosaédricas semelhantes ao capsídeo viral oco, sem o DNA, conhecida como partículas semelhantes ao vírus (VLPs - vírus-like particles), 
possibilitou o desenvolvimento das vacinas contra o HPV, possibilitando reforçar a prevenção primária contra o câncer do colo do útero. ${ }^{5,6}$

As vacinas contra o HPV são produzidas a partir da proteína L1 do capsídeo viral, com o uso da tecnologia de DNA recombinante, obtendo partículas semelhantes ao vírus ou VLP (vírus-like particles). As VLPs são partículas ocas que não possuem DNA viral, dessa forma, não provocam infecção, todavia induzem a produção de anticorpos contra os tipos específicos de HPV presentes na vacina. Além disso, a resposta imunológica específica é gerada por meio de anticorpos neutralizantes contra as proteínas L1 presentes no capsídeo viral. Contudo, a imunização contra a infecção dependerá da quantidade de anticorpos sintetizados, a presença dos anticorpos no local da infecção e a sua persistência durante um longo período de tempo. ${ }^{7,2,8}$, ${ }^{9}$ No Brasil, foi adotada, pelo Ministério da Saúde, a vacina quadrivalente contra os tipos de HPV 6, 11, 16 e 18 (qHPV) (Gardasil ${ }^{\oplus}$, Merck), incorporada no Programa Nacional de Imunizaçóes em 2014. Essa vacina consiste em duas ou três doses aplicadas com intervalo de três a seis meses. A população alvo são meninas na faixa etária de 9 a 14 anos, que não iniciaram atividade sexual, e meninos com idade entre 11 e 14 anos, sendo também oferecida para mulheres até 45 anos com imunossupressão e ofertada no CRIE para pessoas imunodeprimidos, de ambos os sexos, na faixa etária de 9 a 26 anos de idade. ${ }^{2,10,11}$

$\mathrm{O}$ artigo tem por objetivo relatar uma atividade de extensão, desenvolvida durante a pandemia da Covid-19, para promover a conscientização da importância da vacina contra o Papilomavírus humano (HPV) para jovens e adolescentes.

\section{METODOLOGIA}

Trata-se de um relato de atividade de extensão, desenvolvida por acadêmicos do curso de Farmácia da Universidade Regional Integrada do Alto Uruguai e das Missóes, Campus de Santo Ângelo, RS, que ocorreu durante a pandemia da Covid-19, no ano de 2021. Essa atividade de extensão tem como objetivo promover a conscientizaçáo da importância da vacina contra o Papilomavírus humano (HPV) para jovens e adolescentes. Por causa da pandemia da Covid-19, não foi possível realizar as encenaçôes em forma de peça de teatro, como prevista no projeto original. Desta forma, foi desenvolvido um vídeo abordando o tema, como informaçóes sobre a infecção pelo Papilomavírus humano (HPV), transmissão, diagnóstico, prevenção com enfoque na vacina contra HPV. O vídeo foi encaminhado para as professoras das escolas de ensino fundamental e médio, previamente contatadas, para que apresentassem no horário de suas aulas online. Também, foi elaborado um questionário no Google formulário para os estudantes responderem sobre o assunto e colocarem suas dúvidas de forma anônima. As respostas para as questôes, foram devolvidas para as professoras. 


\section{RESULTADOS}

Foi elaborado um vídeo no site "PowToon" para criar uma animação explicativa de forma simples e didática, utilizando figuras e palavras chaves juntamente com narração, explicando o que é o vírus do HPV, formas de contagio e meios de prevenção (Figura 1). Também, foi desenvolvido um formulário com questôes básicas que poderiam ser respondidas com informações mencionadas no vídeo (Figura 2). As questóes de número 1 ao 5 foram realizadas de forma objetiva e apenas a questáo número 6 era dissertativa e opcional. As perguntas realizadas foram: 1) O que é HPV?; 2) Todo tipo de HPV causa câncer?; 3) Qual o câncer mais frequente causado pelo HPV?; 4) Quais as medidas de prevenção contra o vírus?; 5) Você já se vacinou contra o HPV?; e a última, que era uma pergunta aberta - 6) Você ficou com alguma dúvida?

Figura 1 - Imagens do vídeo informativo sobre HPV desenvolvido no projeto de extensão e enviado às escolas.

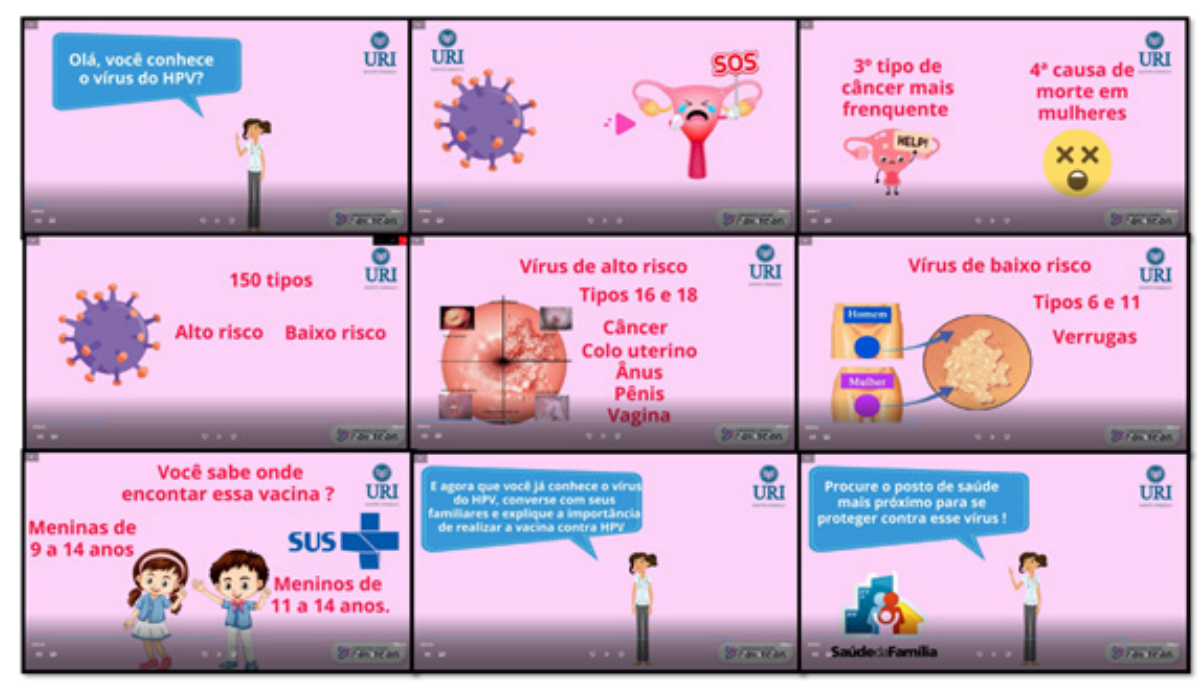

Fonte: os autores

Figura 2- Imagens dos formulários enviados às escolas com questóes básicas que poderiam ser respondidas com informaçōes mencionadas no vídeo.

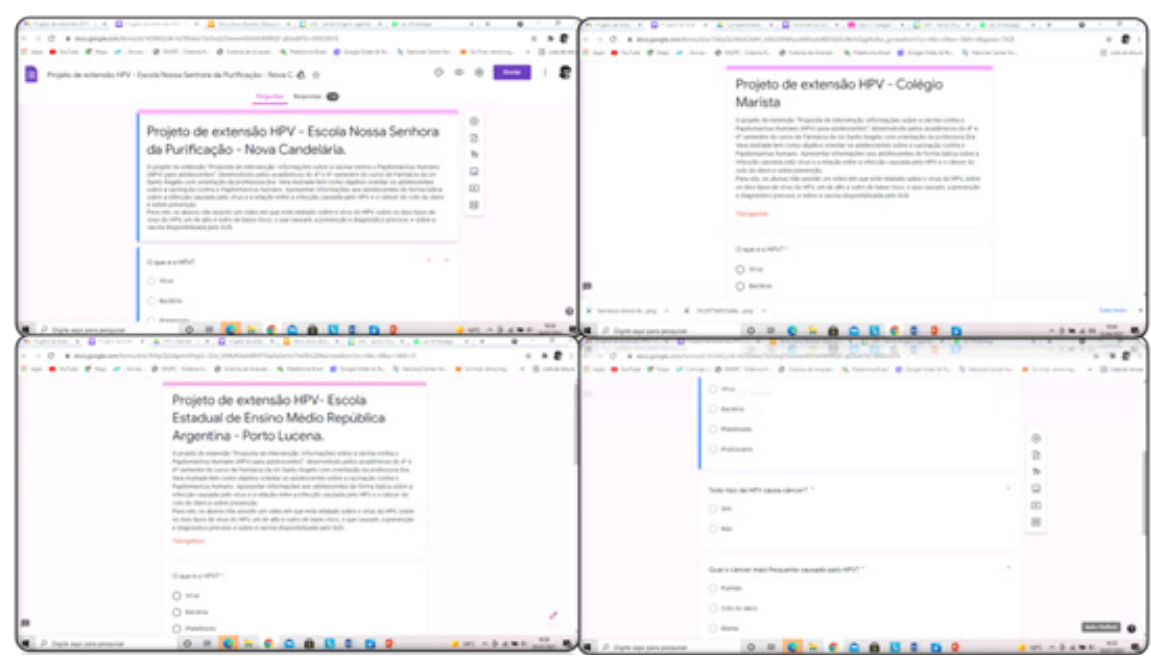

Fonte: os autores 
Foi realizado contato às direçóes e professoras das escolas e foi explicado sobre o projeto e suas finalidades e, após o aceite das escolas, foi encaminhado o vídeo juntamente com o formulário. O vídeo foi enviado para escolas dos municípios de Santo Ângelo, Porto Lucena, Nova Candelária e Roque Gonzales, para alunos do $6^{\circ}$ ao $9^{\circ}$ ano. Para verificar se os alunos assistiram ao vídeo, enviamos junto com o mesmo um questionário realizado pelo Google Formulário. As perguntas enviadas poderiam ser respondidas com informaçôes contidas no vídeo.

O projeto alcançou 4 instituiçôes de ensino, tais como: Colégio Teresa Verzeri em Santo Ângelo, Escola Estadual de Educação Básica Érico Veríssimo - Roque Gonzales, Escola Nossa Senhora da Purificação - Nova Candelária e Escola Estadual de Ensino Médio República Argentina - Porto Lucena. Estão descritas na tabela 1, o número e percentual das respostas das questôes objetivas, visto que não houve dúvidas por parte dos alunos.

Tabela 1 - Número e percentual de alunos que responderam às questóes no Google Formulário sobre o vídeo do HPV.

\begin{tabular}{|c|c|c|c|c|c|c|}
\hline Instituição & $\begin{array}{l}\text { Total de } \\
\text { respostas }\end{array}$ & Questáo 1 & Questáo 2 & Questáo 3 & Questáo 4 & Questão 5 \\
\hline Colégio Teresa Verzeri & 38 & $97,40 \%$ & $52,60 \%$ & $100 \%$ & $94,70 \%$ & $78,90 \%$ \\
\hline $\begin{array}{l}\text { E. E. E. Básica Érico } \\
\text { Veríssimo }\end{array}$ & 12 & $100 \%$ & $58,30 \%$ & $91,70 \%$ & $100 \%$ & $66,70 \%$ \\
\hline $\begin{array}{l}\text { E. Nossa Senhora da } \\
\text { Purificação }\end{array}$ & 120 & $98,30 \%$ & $86,70 \%$ & $98,30 \%$ & $99,20 \%$ & $84,20 \%$ \\
\hline $\begin{array}{l}\text { E. E. E. M. República } \\
\text { Argentina }\end{array}$ & 31 & $87,10 \%$ & $54,80 \%$ & $96,80 \%$ & $96,80 \%$ & $80,60 \%$ \\
\hline
\end{tabular}

Fonte: os autores

\section{CONCLUSÓES}

Concluímos que é importante difundir informações sobre a vacina contra o HPV aos adolescentes e jovens, para que tenham compreensão da prevenção precoce e o quanto ela é necessária, pois por meio dela podemos prevenir a infecção pelo HPV, evitando a evolução de lesôes pré-cancerosas e cancerosas, como o câncer de colo do útero. No entanto, a pandemia da Covid-19 dificultou essa atividade, limitando muito a divulgação destas informaçóes aos adolescentes. 


\section{REFERENCIAS}

1. Brasil. Ministério da Saúde. Instituto Nacional de Câncer José Alencar Gomes da Silva. Estimativa 2020: incidência de câncer no Brasil / Instituto Nacional de Câncer José Alencar Gomes da Silva. Rio de Janeiro: INCA. 2019.

2. Santos ALB, Monteiro CM, Vargas FA. Papilomavírus humano: uma revisão narrativa da literatura. RICSB. 2018.

3. Trujillo E, Sanchéz R, Bravo MM. Integración, carga viral y niveles de ARN mensajero de E2 de VPH 16 en la progresión de lesiones intraepiteliales cervicales. Acta Biológica Colombiana. 2018;23(1):80-87.

4. Montoya AIT, Vela LJT. Virus del papiloma humano (VPH) y cáncer. Medicina \& laboratório. 2021. [Acesso em 6 de julho de 2021]; 25(2). DOI: https://doi. org/10.36384/issn.0123-2576. Disponível em: www.medicinaylaboratorio.com. Acesso em: 6 jul. 2021.

5. Harden ME, Munger K. Human papillomavirus molecular biology. Mutat Res. 2017;772:3-12.

6. Rosa MI, Medeiros LR, Rosa DD, Bozzeti, MC, Silva FR. Silva BR. Papilomavírus humano e neoplasia cervical - Cad. Saúde Pública. 2009;25(5):953-964.

7. Arellano JI, Echezuria L. VPH. Arch Venez Puer Ped [online]. 2011;74(4):159-162. ISSN 0004-0649.

8. Luciani S, Bruni L, Agurto I, Ruiz-Matus C. HPV vaccine implementation and monitoring in Latin America. Salud pública de México. 2019;60:683-692.

9. Sociedade Brasileira de Imunizaçóes (SBIm). HPV. Sociedade Brasileira de Imunizaçôes (SBIm), São Paulo, 2020. [Acesso em: 6 de julho de 2021.] Disponível em: https://familia.sbim.org.br/hpv.

10. Brasil. Ministério da Saúde. Secretaria de Vigilância em Saúde departamento de Vigilância de Doenças Transmissíveis Coordenaçáo-Geral do Programa Nacional de Imunizaçôes. Informe técnico sobre a vacina papilomavírus humano (HPV) na atenção básica. Brasília, DF. 2014.

11. Brasil. Secretaria Estadual de Saúde. Superintendência de Vigilância em Saúde Gerência de Imunização. Guia prático de imunizaçóes para trabalhadores da sala de vacinação. Brasília, DF. 2021;10.

Autor Correspondente: Juliane Oliveira Brum

E-mail: <brumju2000@gmail.com>

Recebido em: 2021-07-20

Aprovado em: 2021-09-14 